\title{
The Bullying Prevention Pack: Fostering \\ Vocabulary and Knowledge on the Topic of Bullying and Prevention using Role-Play and Discussion to Reduce Primary School Bullying
}

\author{
Peadar Donohoe and Carmel O'Sullivan
}

\begin{abstract}
The Bullying Prevention Pack (BPP) is a systematic bullying prevention intervention that fosters learner vocabulary and knowledge about bullying with the use of role-play and discussions. Its aim is to create a heightened awareness of the effects of bullying on peers within the school and to create a defending culture that reduces levels of bullying. Over the course of two school years the BPP was trialled with pupils and teachers in a designated disadvantaged inner city school in Cork. A mixed methods approach was used to analyse the effects of the BPP intervention. Data were gathered from pupils and teachers through learner focus groups, individual interviews, written feedback and the internationally recognised Olweus Bully Victim Questionnaire - Revised to quantify levels of bullying pre and post-intervention. Results indicate that enhanced learner knowledge of the topic of bullying and the use of role-play were significant factors in reducing levels of being bullied.
\end{abstract}

\section{Introduction}

Between 2010 and 2012 a bullying prevention research study employing a novel programme entitled The Bullying Prevention Pack (BPP) devised by Peadar Donohoe was implemented at an inner city school in Cork, Ireland. The BPP is an intervention that aims to enhance learner vocabulary and knowledge on the topic of bullying together with role-plays and discussions that aim to encourage metacognition: "thinking about thinking" (Flavell 1977: 107). This reflective approach about bullying explored the bullying types, the potential players involved in bullying incidents and their effects on peers, and, in this study, it proved successful in developing learner and teacher awareness about bullying behaviour that was occurring in their school. This knowledge fostered an empathetic response that helped to substantially reduce bullying at the research school compared to the control school. Both schools had 
similar demographics, were designated disadvantaged and located in inner city Cork. Prior to the commencement of the intervention pupils in both schools were administered the Olweus Bully Victim Questionnaire-Revised (OBVQ-R) in 2010. The OBVQ-R (Olweus 2006) was the chosen survey instrument as it is internationally recognised and is considered the 'gold standard' assessment for bullying behaviours in schools (Glew et al. 2005: 1030). The choice of this quantitative measure had significant relevance for this study as role-playing methods are quite commonly used for interventions using a qualitative study design but quantitative evidence of their effectiveness is limited (Joronen, Konu, Rankin, and Astedt-Kurki 2011). The quantitative results in this study were significant. By the end of the research learners reported more than a $50 \%$ reduction in reports of victimisation by bullying. The study reveals that the role-plays about bullying and the ensuing discussions were significant factors in reducing bullying at the research school as they enhanced learner vocabulary, knowledge, metacognition and the fostering of empathy. This article will now discuss the particular approach employed in the BPP and the results which emerged from this doctoral study.

\section{The Bullying Definition, Types and Participant Players}

Prior to referencing the literature on the definition and types of bullying and the participant players the BPP instructed teachers to lead classroom discussions with open questions such as: "Does anyone know what the word bullying means?", "What are the types of bullying?", and "Who is involved in bullying incidents?". These open questions were designed to ascertain learner knowledge of bullying behaviour prior to the teacher closing the gap, if any, on the learners' Zone of Proximal Development (ZPD) (Vygotsky 1967) in relation to their knowledge of bullying, through the supplied definitions from the literature which are provided in the pack.

\subsection{Bullying definitions}

There is no internationally agreed definition of bullying (Craig, Henderson and Murphy 2000). From a cross-cultural perspective, one reason for this inconsistency in defining bullying stems from the use of non-universal vocabulary. For example, North Americans tend to use the term 'victimisation'; whereas Scandinavians use the term 'mobbing' when discussing bullying (Craig, Henderson and Murphy 2000). In contrast, most Mediterraneans do not have a specific word for bullying but use overlapping terms that describe a person who has no discipline and order (Kalliotis 2000). In Japan and Korea, there is no direct translation for bullying, but the words 'ijime' and 'wang-ta' refer to social exclusion of the victim by their entire class or year group (James 2010).

Cultural differences aside, a definition that has come to be accepted internationally is based on the work of bullying intervention and prevention pioneer Dan Olweus (Owens, Skrzypiec and Wadham 2012). Olweus is one 
of the most cited researchers on bullying internationally, as well as providing the most widely used and accepted definition (Swearer et al. 2010). Olweus describes bullying as (1) intentional negative behaviour that (2) typically occurs with some repetitiveness and is (3) directed against a person who has difficulty defending himself or herself (Olweus 2011). Teachers at the research school were encouraged to adapt and present the definition of bullying in learner friendly language while giving ample time for discussion. Thereafter, they were encouraged to discuss the types of bullying with their class.

\subsection{Types of bullying}

To begin with, learners were asked open questions about their perceptions of the types of bullying. Thereafter, the following types were introduced by the teacher (O’Moore 2010):

- Verbal bullying name calling/abusive comments which can include slagging, teasing and taunting on how one looks, clothes worn, race, gender, sexuality, religion and/or disability

- Physical bullying includes pushing, shoving, hitting, hair-pulling, scratching, punching, etc., and can include damage to personal property

- Gesture bullying is non-verbal aggression that can include intimidating behaviours such as the cold stare, slitting the throat mime, dirty looks and/or behaviour that mocks someone

- Exclusion/Relational Bullying occurs when a child is isolated from a peer group by preventing her/him from joining in games, school activities and other social activities. Behaviours/actions can include cold shouldering, nasty notes, spreading false rumours and/or offensive graffiti

- Extortion Bullying can include demands/threats for money, possessions or equipment. Targets may also be blackmailed to engage into anti-social acts

- Cyber-bullying can take the forms of text messages, phone calls, online chat rooms and instant messaging

Following the introduction of the bullying definition and types, the learners are introduced to The Bullying Circle (Olweus 1993).

\subsection{Potential players in bullying incidents}

Bullying is often a group process which can involve various participant players (Salmivalli 2010). Salmivalli (2010) suggests that children are not just bullies and/or victims in bullying incidents but can play other parts. For example, they can act as assistants who encourage the bullying behaviour or act as lookouts 
for teachers who might intervene. On the other hand, they may be defenders, who try to stop the bullying. Furthermore, these roles can be fluid (James 2010) as students can play multiple roles in the bully/victim continuum such as engaging in bullying behaviour in one incident, being targeted in another or intervening (Salmivalli 2010). Figure 1 below depicts these potential roles:

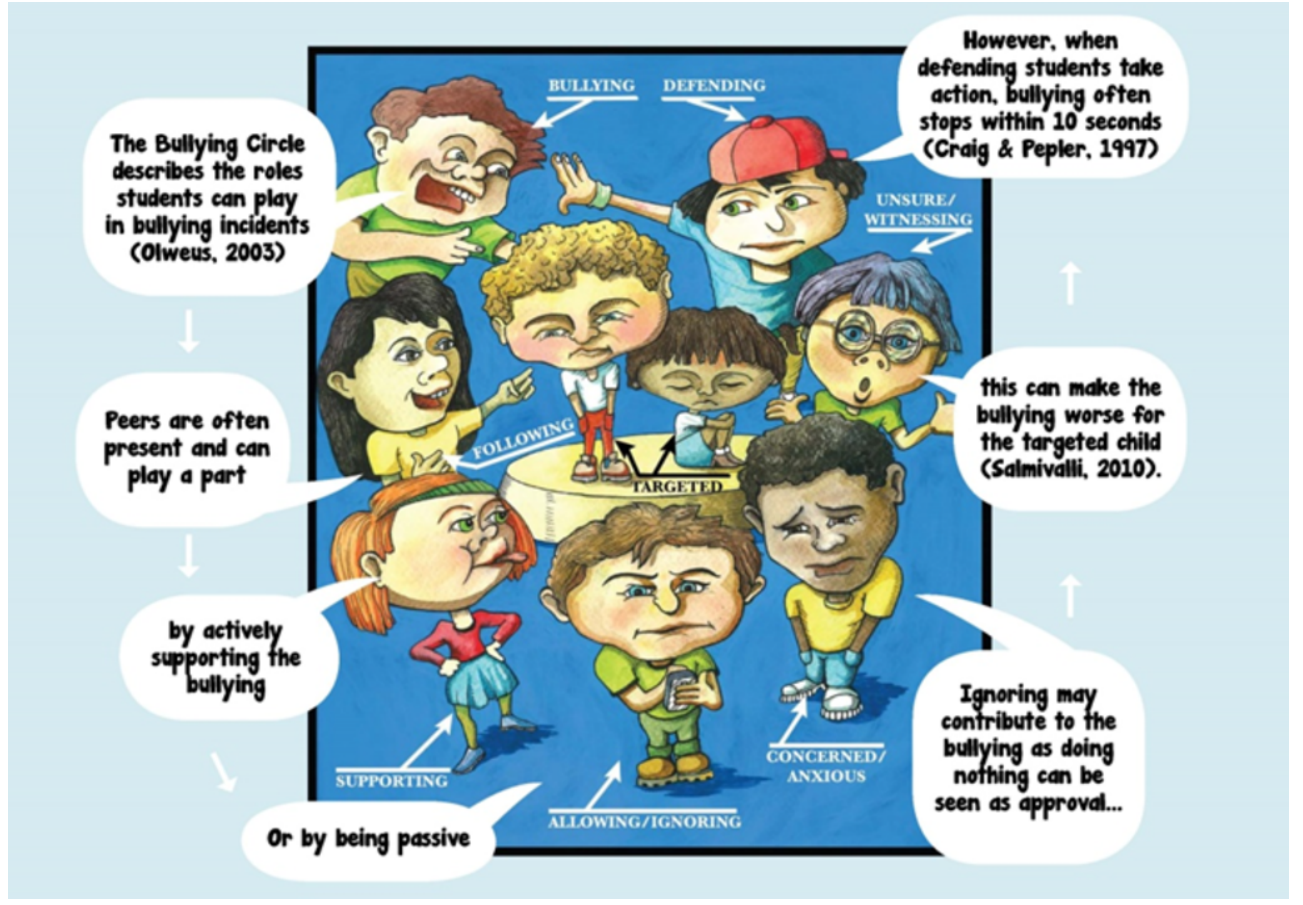

Figure 1: Fig. 1. The Bullying Circle with participant players (adapted by Donohoe and Dummigan, 2015)

The learners were introduced to The Bullying Circle and asked if they could relate these roles to their own experiences. Without naming or blaming any peer, they voluntarily described bullying incidents that happened in the school and were asked to name the type of Bullying Circle players involved.

Once the definition, types and players had been introduced, the learners were then coached to present role-plays on school bullying and be ready to discuss the role-play scenarios demonstrating knowledge using the newly acquired bullying vocabulary.

\section{Exploring Bullying Through Role-play}

\subsection{The significance of role-play as a metacognitive tool}

Over the last sixty years the recognition of role-play's "potential as a valuable education method" (O'Sullivan 2011: 510) has grown both as an educational resource and a research tool. In the classroom setting role-play's constructive 
use can potentially contribute to a learner's understanding of the world, clarifying or modifying it (O'Neill: 1995), helping them to gain skills in social interactions which include the "ability to communicate their understandings and feelings" (Bolton 1979: 71) and to,

...consider ideas from different perspectives, to think of possibilities. Role-play is concerned with representing and exploring different people's points of view, and different points of view forge different types of knowledge. It places participants at the centre of the learning experience, and allows them to build their own bridge of understanding. As a result of this informed consideration, they are better able to resolve problems and issues. (O'Sullivan, 2011: 513)

This 'informed consideration' is a significant goal of the role-plays and ensuing discussions of the BPP which have the aim of helping learners to become more knowledgeable of what bullying is, the part and/or parts they and others could potentially play in bullying incidents which, in turn, might aid their understanding of how bullying affects themselves and their peers emotionally and cognitively. By seeing and perceiving the world from different role perspectives and at the same time being able to relate the role to one's own outlook, the potential for empathy and the understanding of complex situations may be developed (Bagshaw et al. 2005). The fostering of empathy was significant in this study because an empathetic response has been shown to be stunted or lacking in those who engage in bullying behaviour (Gini et al. 2007).

Therefore, it was conceived that a pro-active use of role-play with ensuing questioning and discussion sessions on the topic of bullying, could generate opportunities to create a robust metacognitive peer learning environment where multiple perspectives combine to question and create knowledge as to what bullying behaviour is, the roles peers can in play in promoting or not promoting a bullying culture in their school and making a team effort to create strategies that are preventative in nature.

\subsection{Role-play implementation}

The BPP was enacted over a five-week period in years 1 and 2 of the study. The first four weeks were concerned mainly with creating knowledge about bullying through the use of role-play scenarios and ensuing discussions. These discussions helped to re-inforce the knowledge of bullying from the literature and also to understand how bullying was manifesting in the school and affecting individuals. The BPP session content was divided as follows:

Week 1: Bullying in our school: Discussions as to what learners knew about bullying, the forms it can take in the school and a review of the definition and types from the literature

Week 2: Bullying role-plays: Introduction to the participant players in bullying incidents, followed by improvised learner role-plays on school bullying. Roleplays were followed by a question and discussion session that addressed the following questions: 
- Does it keep happening? Was it bullying or a once-off incident? [The repetitive nature of the aggressive act is a key part of the definition of bullying (Irish Action Plan on Bullying 2013)]

- What type(s) of bullying was it?

- Which Bullying Circle players were involved?

- How do you think the targeted child felt?

- What were the others thinking/feeling?

Week 3: Onlooker Role-play: The role of the onlooker and what they could possibly do to help was discussed. Then, through modelled and improvised roleplays, learners were encouraged to report bullying and defend the victimised child. Significantly, teachers were advised that the role of the defender should be played by a popular child. This strategy was proposed because research has shown that popular children can be an influential resource in changing classroom attitudes to bullying (Dijkstra, Lindenberg \& Veenstra 2008). The social status of group members impacts upon the end result of the group's thinking as ideas from students with higher peer social status are more likely to be valued, while ideas from students with lower peer social status are likely to be ignored, rejected, or absent: "The nature and quality of the relationships between the participants in a group also contribute to the degree to which the interactions among the participants are successful" (Dijkstra, Lindenberg \& Veenstra 2008: 230). Hence, awareness of the influence of the popular child as a defender was crucial to the overall success of class group endeavours to counteract and prevent bullying.

Week 4: Defending with Confidence: In these suggested role-plays the learners were asked to display confident behaviour when defending. As an aid to the collective efficacy to prevent bullying in their school all children were coached in defending with confident behaviour. Children who bully tend to pick on children who have low status in the social group (Matthews \& Kesner 2003). Children who display low status behaviour may be giving cues to their peers that shows they are not confident and secure (i.e. poor eye contact, fidgety gestures, poor posture) (Pierse 1995). To counteract this, the Confident Behaviours Exercise, which was devised by Peadar Donohoe, is played as a way to help children become more aware of behaviours that display high and low confidence. The participating teachers introduced the exercise by asking the learners what the word 'confidence' meant to them. Learner answers were noted and discussed. If needed, the teacher also provided the following definition: "belief in yourself and your abilities". The class was split into two, with the teacher ensuring that there were learners of varying confidence levels in each group. One group, Group High Confidence, stands to one side of the room and Group Low Confidence on the other. The teacher assigns the behaviours (listed below) to the respective assigned groups and asks them to show what the behaviour would look like. The teacher coaches if necessary. 
The exercise was then repeated vice versa so that all children had a chance to model confident behaviours. After coaching the exercise, the teacher then asked four volunteers to participate in a defender role play and assigned the parts of bully, follower, victim and defender. The instructional strategy was to encourage the learners to use confident behaviours from the exercise within their role-play. Once this was coached and understood by the group, the entire class was asked to create role-plays where the defender employed confident behaviours.

Week 5: The Contract: Learners signed a contract to prevent bullying in their school. At this point in the BPP intervention the aspiration was for learners to be able to:

- define, identify and discuss bullying types;

- discuss the participant players in The Bullying Circle;

- relate how bullying behaviour affects oneself and one's classmates, and have greater understanding and empathy regarding the thoughts and feelings of others who have experienced bullying;

- know what steps to take if they found themselves a target of bullying;

- demonstrate confident behaviours;

- show how to defend by reporting to someone in authority or intervening if they feel safe and supported.

The content of the contract re-iterated this knowledge along with learners' ideas and methods to prevent bullying that also took into account the school's anti-bullying policy and procedures.

After the initial five-week intervention there were monthly check-ups by the class teacher. The exact content of these sessions was left to the discretion of the individual teacher who is in the best position to assess learners' needs or deficits with regards to bulling vocabulary and/or knowledge. However, suggested topics included a review of the bullying lexicon including the definition, typology, Bullying Circle players, discussions on bullying incidents that may have occurred (without naming or blaming) and discussions about whether agreed procedures to counteract bullying were working or not, role-playing bullying scenarios, discussing bullying, review of the contract, and creating amendments/changes to the contract if needed. The main aim of these follow-up sessions was to keep the contract fluid and responsive to learner needs with regards to bullying behaviour and to reinforce the message that the school authorities were supportive of The BPP initiative in the long term. This was a specific recommendation of the BPP, as the literature suggests that schools, which have high levels of prevalence, often do not have a culture that supports interventions over time (Polanin, Espelage and Pigott 2012; Ttofi and Farrington 2011). 


\section{Methods}

The research group involved a total of 231 male primary school pupils (55 in year 1 and 176 in year 2), and 13 teachers (3 in year 1 and 12 in year 2). Alongside qualitative evidence, the study employed the OBVQ-R to generate quantitative evidence to examine the impact of the BPP at both the research and a similarly sized control school. For the quantitative analysis a comparison was made between the fourth, fifth and sixth classes at the research and control schools. Both were designated disadvantaged schools and located in inner city Cork. The control school had a total school population of 150 students, 14 teachers with 61 learners in the fourth, fifth and sixth classes that could potentially participate in the OBVQ-R survey. The numbers present on the survey implementation days were as follows: in December, 2010, the research school had 52 students self-reporting in the pre-intervention analysis and 52 reporting in June, 2011. The control school had 57 self-reporting in December, 2010, and 55 in June, 2011. For the May, 2012, survey 30 students self-reported at the research school and 35 at the control school. The reduction in numbers in May, 2012, is due to the fact that by the end of the second year only the fifth and sixth class learners had completed the questionnaire, as the sixth year pupils who participated in the first year of the intervention had moved on to secondary school. Hence, the overall amount of respondents had decreased.

The qualitative data collection strategy at the research school included weekly written teacher feedback and individual face to face meetings while the intervention was being implemented, learner focus groups each year (fourth, fifth and sixth class in the first year - the third class was included in the second year), teacher interviews in the second year, and an interview with the school principal at the study's end.

Initially, the plan for the intervention in the research was to track the boys of the fourth, fifth and sixth class in year one, and to track the same fourth and fifth class learners who had progressed to fifth and sixth class respectively in year two. However, in September 2011, the principal indicated that they were very pleased with teacher and learner reports of bullying being reduced at the research school and asked for the BPP to be used on a whole school basis for the 2011-12 school year. While this was unexpected, it provided an opportunity to see if the programme could be implemented on a whole school basis as evidence from the literature suggests that bullying prevention efforts on a whole school basis tend to be more successful (Thompson and Smith 2011; Ttofi and Farrington 2011 ).

\subsection{Teacher data}

An overview of teacher data in year two of the study, analysed according to emergent themes, is presented in Table B below. The junior strand represents feedback from junior infants to first class (five classes in total, ranging in age from 5-7 years) and the senior strand represents second class to sixth class (five 
classes in total, ranging in age from 8-12 years).

Overly long instructions was a common theme reported by both strands. The BPP hand-outs were initially designed to provide detailed information and instruction so that teachers would be well informed about current research on the bullying phenomena. However, teachers pointed out that they were very busy and needed concise information and jargon-free instructions in a bullet point format if possible. The amended handouts in the BPP were well received in the second year of the study.

Role-play was reported as problematic for some teachers in the junior strand. The senior infants and first class teachers noted that the role-plays were over the learners' heads. In contrast the 2 junior infants' teachers reported that they had no issues with the Bully Enactment, Reverse and Onlooker role-plays but noted that the Defender Role-play was 'too complicated' for their young pupils.

With regards to knowledge of bullying typology, once-off incidents of aggression were being reported as bullying during the intervention. This was noted as an issue in both strands and teachers reported that they had to be consistent in their instructions to learners that bullying incidents had to be repetitive and intentional in order to be considered bullying. Junior strand teachers were encouraged to use their discretion with the amount of bullying types and the Bullying Circle players introduced to young learners and, they reduced the vocabulary in these areas with good results.

Discussing their own experiences proved to be a key area for developing the learners' metacognition in this study as talking and questioning each other's views is acknowledged in the literature as engaging learners intellectually, emotionally and socially (Boud 2001). This approach in the BPP of encouraging peer learning as a metacognitive strategy was highlighted by the third class teacher: "They listen to their peers far more than me". With regards to the fostering of empathy, a junior infants' teacher reported that discussing feelings had a positive effect in reducing bullying:

"They are much more aware of the effects it has on other people. That's one of the biggest benefits that they see how it could hurt other boys in the classes. It's amazing. Even their behaviour towards one another in the class has been positively affected as well as out in the yard."

In the senior strand teachers reported that the activity of doing the role-plays was significant for empathy generation and creating knowledge about bullying. The third class teacher reported her thoughts on this, "Getting to act it out and empathise with their character that was very important for their understanding of bullying".

Overall, the teachers in both strands reported that the discussions, following the role-plays, were a positive strategy for talking about feelings and fostering empathy. Significantly, the 'no name, no blame' approach (Maines and Robinson 1997) adopted by the BPP aided the discussions as described here by Craig, a fourth class participant: "It was easy because we didn't have to name out names and we could just tell out what happened without feeling bad about it". 


\subsection{Review of learner qualitative data}

There were three main objectives of the learner focus groups: 1) to ascertain their knowledge and understanding of the bullying topic, 2) their ability to defend, and 3) if they felt that bullying had been reduced at their school. The data which follows is compiled from transcriptions of the focus groups which took place with representative samples of six learners from each the participating third, fourth, fifth and sixth classes. An overview of the data is presented in Table $\mathrm{C}$ below.

By the end of the study, all focus groups reported that they understood bullying as repeated aggression. The data supports the claim that this important part of the definition of bullying had been successfully communicated to them by their teachers and through using the BPP.

Learners reported that overall they were confident defenders whether it was by direct peer-to- peer intervention or reporting bullying incidents to a trusted adult. The approach of reporting to a teacher was commonly cited by the learners, as their belief in the teacher efficacy in dealing with a bullying incident had strengthened. With regards to this belief, Jim of third class noted: "It's easy to talk about it because I know I can talk to the teacher who will do something about it". This view echoes research which asserts that interventions which have a lasting impact are those in which the learner has a strong belief and faith in the teacher's ability to deal with bullying (Action Plan on Bullying 2013; Smith 2011).

All groups indicated that the 'no name, no blame' approach (Maines and Robinson 1997) to talking about bullying incidents was a significant aid to the discussions. Overall the discussions about bullying incidents and how it made the learners feel received very positive reports from each class group. However, there were a small number of learners with reservations on the topic of discussing feelings, such as Michael in fifth class who reported his fear that "they'd all mock us". Kevin of third class said that after he shared his story of being bullied he "felt a little more sadder". However, awareness of these sad feelings had a positive effect in that it aided the engendering of empathy in many students, with Philip of third class reporting that the awareness of his 'feeling sad' made him more willing to help a student who was bullied: "I would feel sad and feel I would have to do something for him".

Overall, learners perceived that there was a reduction in bullying in their school and this was also reflected in the quantitative data.

\subsection{Results from the Olweus Bully-Victim Questionnaire - Revised (OBVQ-R)}

The OBVQ-R is comprised of 39 questions about being bullied, bullying others and perceptions of bullying. For the purposes of this article, data from a selected number of relevant questions will be presented. Pupil responses to question four, "How often have you been bullied?" are considered particularly significant 
for gauging overall levels of school bullying victimization (Olweus 2007) and are of prime interest to this research.

In December, 2010, June, 2011, and May, 2012 the OBVQ-R surveys were administered at the research and control schools. At the research school teachers were coached on BPP implementation. This continued for two school years. At the conclusion of the intervention, the May 2012 surveys indicated in the categories of victimisation by bullying that there was a $53.7 \%$ increase at the research school whereas at the control school there was an increase of $16.9 \%$ in reports of victimisation by bullying at the control school.

Figure 2 shows that at the research school in December $201059.6 \%$ of pupils reported not being bullied, with $5.8 \%$ of pupils reported being bullied several times a week. Results from the control survey were comparable as can be seen in Figure 3.

\section{Pre-intervention/Question 4/ Control School: How often have you been bullied?}

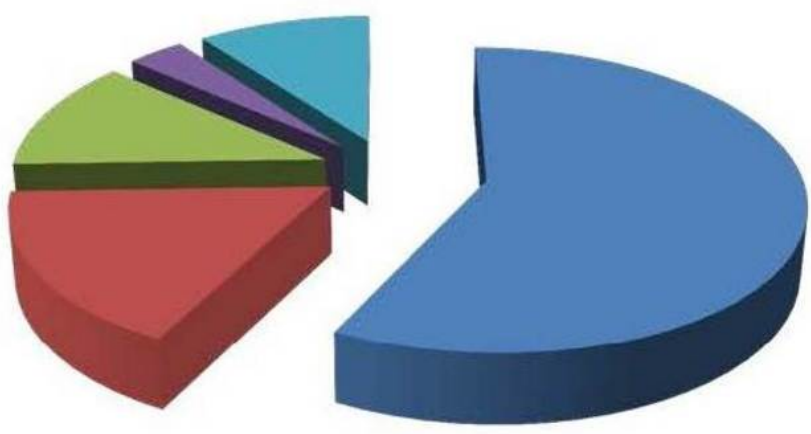

Not at all: $57.6 \%$

1 or 2 times: $16.9 \%$

2 or 3 times: $11.9 \%$

Once a week: $3.4 \%$

- Several times a week: $10.2 \%$

Figure 2: Learner responses to OBVQ-R Question 4 pre-intervention, control school (December, 2010)

Figure 4 provides a direct comparison between the research and control schools with victimization reportage at $40.5 \%$ at the research school and $42.4 \%$ at the control school.

Comparing these percentages to other surveys conducted in Ireland ${ }^{1}$ is insightful:

1. A nationwide survey conducted in 1997 (O'Moore, Kirkham and Smith) found that $31 \%$ of Irish primary pupils reported were being bullied.

2. The Health Behaviour in School-aged Children (HBSC) survey (Walsh, Clerkin and Nic Gabhainn 2002) found that $23.3 \%$ of primary school children reported being bullied.

\footnotetext{
${ }^{1}$ In Ireland the education sector comprises national primary and non-aided private primary schools. Education at primary level comprises standards 1 to 6 with children enrolled from age 6.
} 
3. In the $A B C$ survey the numbers reported being bullied in primary schools was $15.6 \%$ (Minton and O'Moore 2008).

4. The Growing Up in Ireland (2009) survey showed that $40 \%$ of nine-yearolds reported being victims of bullying in the previous year.

5. In a 2010 survey that combined reports from primary and secondary school children, $24.3 \%$ of respondents aged between $10-17$ reported that they were bullied at school at least once in the past couple of months (Callaghan et al. 2010).

6. In a more recent survey of Irish secondary school pupils conducted by Minton (2010) 35.3\% was the average reportage of victimisation.

Comparing this data to the study results reveals that both the research and the control schools are at the top of the bullying reportage range with victimisation rates of over $40 \%$ each. This may be attributable to the fact that both are inner city schools and designated disadvantaged. It has been reported in the literature that schools in low income areas tend to have higher levels of bullying (Farrington 1993) with Rosenstein-Manner (1991) reporting higher levels of bullying in inner city schools. Internationally, the phenomenon of low income appears to correlate with higher levels of bullying with more than half of the student population of low to middle income countries reporting that they experience bullying (UNICEF 2014).

Responses to the post-intervention survey in 2012 demonstrate that there was a significant decrease at the research school compared to the control school as depicted in the figures below.

Figures 5 and 6 illustrate the differences in victimisation reporting between the research and control schools near the end of the school year 2012. At the control school a pupil had a $57 \%$ greater likelihood of being victimised by bullying than at the research school. Looking solely at the levels of bullying reportage at control school in Figure 6, student responses show that there was a $16.9 \%$ increase in victimization by bullying over the 18 -month period from December 2010 to May 2012.

Figure 7 below puts into sharp relief the reportage of bullying at the research and control schools through direct comparison.

Figure 7 illustrates reportage of bullying victimization as a whole, regardless of frequency compared to non-reportage. The survey data shows that there was a $119.7 \%$ bullying victimization reportage differential between the research and the control schools by the end of the research period (research school 23.4\%, control school, 51.4\%) whereas at the start of the study the differential was only marginal (research school $=40.5 \%$, control school $=42.4 \%$ ). Therefore, the data clearly demonstrates that learners perceive a reduction in bullying at the research school. The only variable reported from the research school principal during the 18-month study period which would not have impacted upon the results was the introduction of the BPP. 


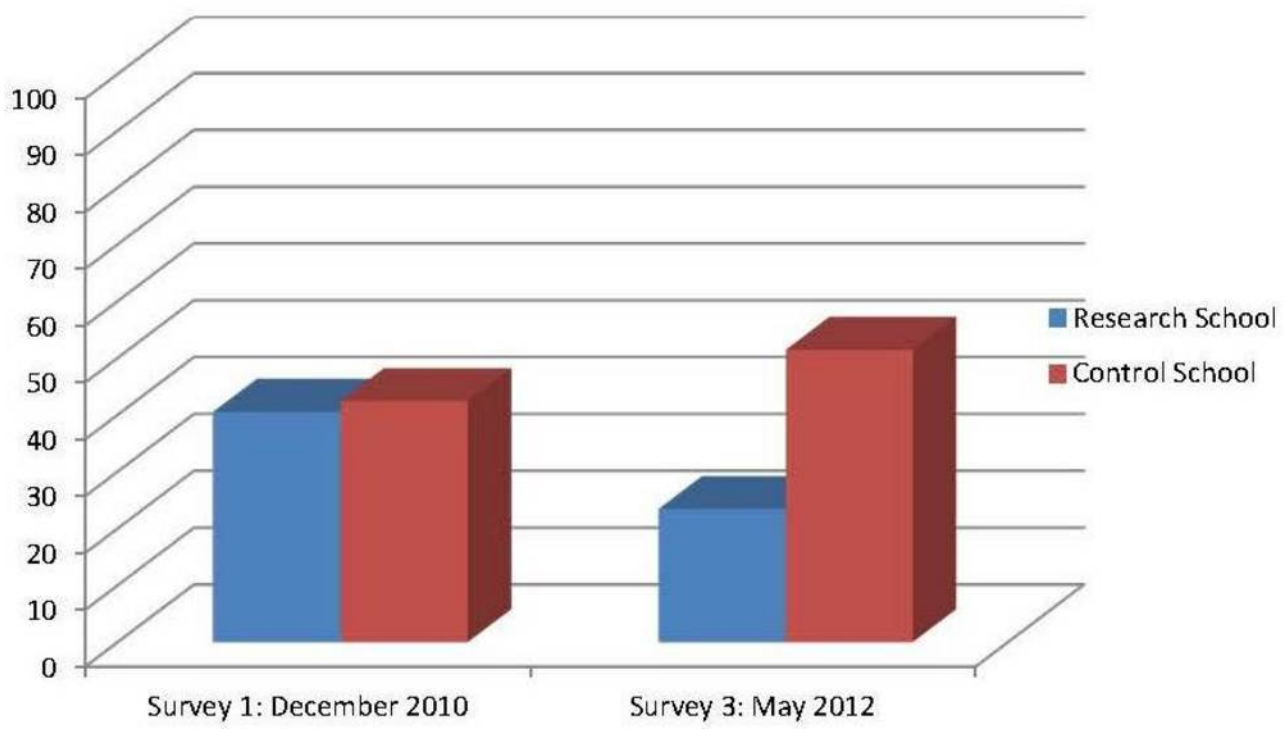

Figure 3: Comparison of bullying victimization reportage at the research and control schools pre and post-intervention

\section{Conclusion}

The survey results provide strong quantitative evidence that the BPP was effective in reducing bullying over the long term. This was also confirmed by the qualitative data from the teachers and learners which support a strong majority perception that bullying was reduced at their school. The evidence from this research study suggests that one of the main reasons for this were the interactive role-plays that engendered peer learning. The following quote from the sixth class teacher is reflective of this prevalent attitude as reported in the data. When asked to sum up his thoughts on the BPP implementation after 18 months, he said:

"The drama, the fact that they are learning about bullying, the terms, the definitions, they are learning it through role-plays, they are actually able to link in their heads what physical bullying is with the drama they've done. [...]They have a link in their heads so they know what it is. So they can very quickly identify it. And they know the steps in how to deal with it again because they've dealt with it through drama in the class. They know what from a to $b$ to $c$ to $d$ should be. They know the steps and how to do it. I found that as a teaching aid it has been brilliant, a very good idea in how to deal with bullying. I personally found it very helpful."

The evidence from this study supports the claim that the BPP's emphasis on creating knowledge about bullying by fostering vocabulary on bullying typology, and by reviewing the learners' experience of bullying with role-plays and ensuing discussions, was instrumental in reducing the levels of bullying at 
the research school. By the end of the intervention learners were better able to identify and discuss their feelings and those of others at length. The role-plays and discussions were mutually generative in creating empathy. This potential is summed up by the third class teacher:

"It was just theory but actually putting it into practice, exploring difficult issues through the fictional lens is very important. Getting to act it out and empathise with their character that was very important for their understanding of bullying. If we didn't have the role-plays, I don't think it would have been half as effective."

This study has provided clear evidence that the ensuing discussions based on the role-play content strengthen learners' empathy and knowledge further, thereby laying the foundation for a robust and pro-active anti-bullying school environment.

\section{Bibliography}

Bagshaw, Dale; Friberg, Mats; Lepp, Margaret; Lofgren, Horst; Malm, Bridget; O’Toole, John (2005): The Dracon Project: Bridging the Fields of Drama and Conflict Management: Empowering students to handle conflicts through school-based programmes. School of Teacher Education: Malmö University, Sweden

Bolton, Gavin M. (1979): Towards a Theory of Drama in Education. Burnt Mill: Longman Group Limited

Boud, David (2001): Introduction: Making the Move to Peer Learning. In: Boud, David; Cohen, Ruth \& Sampson, Jane (eds.): Peer Learning in Higher Education: Learning From \& With Each Other. London: Kogan Page Ltd

Callaghan, Mary; Clarke, Nancy; Gavin, Aine; Kelly, Colette; Molcho, Michal; Nic Gabhainn, Saoirse; Walker, Lynne (2010): Bullying behaviour among schoolchildren in Ireland, Health Behaviour in School-aged Children. Galway: National University of Ireland

Coloroso, Barbara (2004): The bully, the bullied, and the bystander: From Preschool to High School - How Parents and Teachers Can Help Break the Cycle of Violence. New York: Harper Collins

Craig, Wendy M.; Henderson Kathryn \& Murphy, Jennifer (2000): Prospective teachers' attitudes toward bullying and victimization. In: School Psychology International 21, 5-21

Department of Education and Skills (2013): Irish Action Plan on Bullying. Report of the Anti-Bullying Working Group to the Minister for Education 
and Skills. Dublin: The Stationery Office. Available at: https://www. education.ie/en/Publications/Education-Reports/Action-PlanOn-Bullying-2013.pdf [last accessed July 28, 2015]

Dijkstra, Jan Kornelis; Lindenberg, Siegwart \& Veenstra, René (2008): Beyond the class norm: Bullying behavior of popular adolescents and its relation to peer acceptance and rejection. In: Journal of Abnormal Child Psychology 36, 1289-1299

Donohoe, Peadar \& Dummigan, David (2015): The Bullying Circle - Revised. Adapted from Dan Olweus' Bullying Circle with permission. Cork: Cyclone Publications

Farrington, David P. (1993): Understanding and Preventing Bullying. In: Crime and Justice 17, 381-458

Flavell, James H. (1977): Cognitive development. Englewood Cliffs, NJ: Prentice-Hall

Gini, Gianluca; Albiero, Paolo; Benelli, Beatrice; Altoè, Gianmarco (2007): Does empathy predict adolescents' bullying and defending behavior? In: Aggressive Behavior 33, 467-476

Glew, Gwen M.; Fan, Ming-Yu; Katon, Wayne; Rivara, Frederick P.; Kernic, Mary A. (2005): Bullying, psychosocial adjustment, and academic performance in elementary school. In: Paediatrics \& Adolescent Medicine $159,1026-1031$

James, Alana (2010): School Bullying. National Society for the Prevention of Cruelty to Children, London. Available at: http://westmidlandssafeguarding . westmidlands.nhs.uk/ul/school_bullying_pdf_wdf73502.pdf [last accessed July 28, 2015]

Joronen, Katja; Häkämies, Annukka \& Åstedt [U+2010] Kurki, Päivi (2011): Children's experiences of a drama programme in social and emotional learning. In: Scandinavian Journal of Caring Sciences 25, 671-678

Kalliotis, Panayiotis (2000): Bullying as a special case of aggression: Procedures for cross-cultural assessment. In: Psychology in the Schools 21, 47-64

Maines, Barbara \& Robinson, George (1997): Crying for Help: the no blame approach to bullying. Bristol, UK: Lucky Duck Publishing

Matthews, Mona W. \& Kesner, John E. (2003): Children learning with peers: The confluence of peer status and literacy competence within small group literacy events. In: Reading Research Quarterly 38/2, 208-234 
Minister for Health and Children (2009): Growing Up in Ireland, the National Longitudinal Study of Children, The Lives of 9-Year Olds Executive Summary, Office for the Minister of Children and Youth Affairs. Dublin: The Stationery Office

Minton, Stephen J. \& O'Moore, Astrid Mona (2008): The effectiveness of a nationwide intervention programme to prevent and counter school bullying in Ireland. In: International Journal of Psychology and Psychological Therapy 8, 1-12

Minton, Stephen J. (2010): Students Experiences of Aggressive Behaviour and Bully-Victim Problems in Irish Schools. In: Irish Educational Studies $29,131-152$

Olweus, Dan (1993): Bullying at school: What we know and what we can do. Oxford: Blackwell Publishers

Olweus, Dan (2006): Olweus Bully/Victim Questionnaire (Revised), received from Mr. Olweus, May 5, 2010

Olweus, Dan (2007): Olweus Sample Standard School Report. Center City, MN: Hazelden.

https://www.pdastats.com/PublicFiles/Olweus_Sample_Standard_School_ Report.pdf

[last accessed July 28, 2015]

Olweus, Dan (2011): Bullying at School and later criminality: findings from three Swedish community samples of males. In: Criminal Behaviour and Mental Health 21, 151-156

O’Moore, Astrid Mona; Kirkham, Colin \& Smith, Murray (1997): Bullying in Irish Schools: A Nationwide Study. In: Irish Journal of Psychology 18, 141-169

O'Moore, Astrid Mona (2010): Understanding School Bullying: A Guide for Parents and Teachers. Dublin: Veritas

O'Neill, Cecily (1995): Drama worlds: A framework for process drama. Portsmouth, NH: Heinemann

O'Sullivan, Carmel (2011): Role-Playing. In: Cohen, Louise; Lawrence, Manion \& Morrison, Keith (eds.): Research Methods in Education (7th ed.). Oxon: Routledge

Owens, Larry; Skrzypiec, Grace \& Wadham, Ben (2012): Thinking patterns, victimisation and bullying among adolescents in a South Australian metropolitan secondary school. In: International Journal of Adolescence and Youth 19, 190-202 
Pierse, Lynne (1995): Theatresports Down Under: A Guide for Coaches and Players. Sydney: Improcorp

Polanin, Joshua R.; Espelage, Dorothy L. \& Pigott, Theresa D. (2012): A meta-analysis of school-based bullying prevention programs' effects on bystander intervention behavior. In: School Psychology Review 41, 647654

Rigby, Ken \& Johnson, Bruce (2006): Expressed readiness of Australian school children to act as bystanders in support of children who are being bullied. In: Educational Psychology 26, 425-440

Salmivalli, Christina (2010): Bullying and the peer group: A review. In: $A g$ gression and Violent Behaviour 15, 112-120

Smith, Peter K. (2011): Why interventions to reduce bullying and violence in schools may (or may not) succeed: Comments on this Special Section. In: International Journal of Behavioral Development 35, 419-423

Swearer, Susan; Siebecker, Amanda; Johnsen-Frerichs, Lynae; Wang, Cixin (2010): Assessment of Bullying/Victimization: The problem of comparability across studies and across methodologies. In: Jimerson, Shane; Swearer, Susan \& Espelage, Dorothy L. (eds.): Handbook of bullying in schools: an international perspective. New York: Routledge, 305-328

Thompson, Fran \& Smith, Peter K. (2011): The Use and Effectiveness of AntiBullying Strategies in Schools. London: DFE

Ttofi, Maria M. \& Farrington, David P. (2011): Effectiveness of school-based programs to reduce bullying: A systematic and meta-analytic review. In: Journal of Experimental Criminology 7, 27-56

United Nations Children's Fund (2014): Hidden in Plain Sight: A statistical analysis of violence against children. Division of Data, Research and Policy. New York: UNICEF

Vygotsky Lev (1967): Play and its Role in the Mental Development of the Child. Psychology and Marxism Internet Archive. http://www. marxists. org/archive/vygotsky/works/1933/play.htm [last accessed July 23, 2015]

Walsh, Kieran; Clerkin, Pauline \& Nic Gabhainn, Saoirse (2002): Bullying Among Irish School Children. HBSC Ireland Research Factsheet No.8. Galway, Health Promotion Research Centre. http://www. nuigalway . ie/hbsc/documents/factsheet_8.pdf [last accessed July 29, 2015]

Zeigler, Suzanne \& Rosenstein-Manner, Merle (1991): Bullying in School. Toronto: Board of Education 